\title{
New model for the rehydration characteristics of white yam at different temperatures
}

\author{
Akinola, A. A. ; Ezeorah, S. N.; Nwoko, E. P. \\ ${ }^{\text {a }}$ Department of Chemical and Petroleum Engineering, University of Lagos, Lagos, Nigeria. \\ *E-mail of the corresponding author: akinjideakinola@gmail.com
}

\begin{abstract}
A new model describing the variation in the rehydration ratio with rehydration time for yam slices is presented here. Also presented, is a new model for the rehydration kinetics of yam slices. Mass and moisture content rehydration data were collected while rehydrating $3.0 \mathrm{~mm}$ thick dehydrated yam slices. Regression analysis established that the mass rehydration data better fitted a two-term exponential equation rather than a second-order polynomial equation. Also, for the rehydration kinetics, the moisture content rehydration data was better fitted to a new empirical model rather than the Weibull, Peleg, and Exponential models.
\end{abstract}

Keywords: Rehydration Ratio Models; Rehydration kinetic models; Yam; Weibull, Peleg, and Exponential models. 


\section{Introduction}

White yams (Dioscorea rotundata) are very nutritious and are an excellent source of energy and dietary fiber ${ }^{[1,2,3,4,5,6]}$. Yams are eaten routinely and they constitute a dominant portion of the standard diet for many people. They are used, worldwide, in many different recipes. For this reason, there is a need for these commodities to be transported to the many locations where they are consumed. However, they are heavy, constituting of at least $70 \%$ water. Dehydrating yams like most foods and agricultural products are becoming an essential method of processing before being shipped to where they will be consumed. Dehydration is also performed for preservation purposes.

The dependence of many dehydrated food and agricultural commodities in the present marketplace is increasing as this is a means of extending the length of time that the products may be stored without becoming unfit for future use. Rehydration operations, therefore, are gaining importance as these dried products will need to be rehydrated before use. There is, therefore, need to understand the issues relating rehydration operations concerning the design and the operations of these processes.

Mathematical modeling has been useful in the study, design, optimization, and operations of these rehydration processes ${ }^{[7,8]}$. This study involves investigating the rehydration kinetics and estimating other rehydration characteristics of the dehydrated products.

The models that have been used to study the rehydration characteristics of foods are the

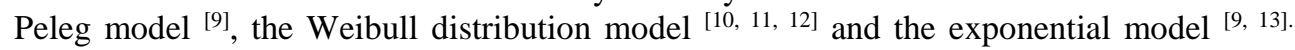
However, for accurate use of these models, more knowledge, in addition to the rehydration data and knowledge of some physical parameter(s) of the product being studied, is required. For the Peleg, ${ }^{[14]}$, Weibull distribution and Exponential models knowledge of the initial moisture content before rehydration is required. For the Exponential model, the equilibrium moisture content also, needs to be known; and for the Weibull model, knowledge of scale and shape parameters of the samples are required ${ }^{[15]}$. Presented in this study is a new rehydration model for yam that requires only the moisture content rehydration data, and a comparison of all the four (4) rehydration models are performed.

\section{Materials and Methods}

\subsection{Sample Preparation}

White yam tubers acquired from the local market were washed, peeled, cut into $3 \mathrm{~mm}$ thick slices. The slices were dried in a Refractance Window ${ }^{\mathrm{TM}}$ dryer until the moisture content was about $0.03 \mathrm{~g}$-water/g-solid. The dehydrated samples were kept in air-tight polyethylene bags and stored in a refrigerator until further use in the rehydration experiments.

\subsection{Rehydration experiments}

The dried samples were brought to room temperature before starting the rehydration experiments. Rehydration of the samples was done in $250-\mathrm{mL}$ beakers filled with distilled water. The beakers were immesed in a thermostatically controlled water bath, and each set of experiments was performed at $27^{\circ} \mathrm{C}, 40^{\circ} \mathrm{C}, 60^{\circ} \mathrm{C}$ and $80^{\circ} \mathrm{C}\left( \pm 0.5^{\circ} \mathrm{C}\right)$. Approximately $3.75 \pm 0.25 \mathrm{~g}$ was immersed in $100 \mathrm{ml}$ of distilled water for periods of $10,20,30,40,50$, 
$60,80,100,120,150,180,210$ and 240 minutes. The temperature of the water inside the beakers was determimed with a thermocouple. A perforated plexiglass cup was used to cover the samples to ensure they were entirely immersed in the water in the beakers during rehydration. After rehydration, the water was drained from the flask, and excess water on the samples was removed using tissue paper. The samples were then weighed. The moisture content of the samples was determined using an OHAUS moisture analyser ${ }^{[16]}$. Every experiment was done in triplicate.

\subsection{Modelling The rehydration ratio}

The rehydration ratio (RR) was calculated according to equation 1.

$\mathrm{RR}=\mathrm{W}_{\mathrm{t}} / \mathrm{W}_{\mathrm{o}}$ where $\mathrm{W}_{\mathrm{t}}$ is the mass of rehydrated sample at time $t$ and $\mathrm{W}_{\mathrm{o}}$ is the initial mass of sample to be rehydrated.

The rehydration ratios and rehydration times were correlated first according to the two term exponential equation of the form given in equation 2 and then with the second order polynomial equation of the form given in equation $3^{[17]}$.

$\mathrm{RR}==\mathrm{p}_{1} * \exp \left(\mathrm{p}_{2} * \mathrm{t}\right)+\mathrm{p}_{3} * \exp \left(\mathrm{p}_{4} * \mathrm{t}\right)$ where $\mathrm{p}_{1}, \mathrm{p}_{2}, \mathrm{p}_{3}$, and $\mathrm{p}_{4}$, are constants observed from regression analysis and $\mathrm{t}$ is the rehydration time in minutes.

$\mathrm{RR}=\mathrm{p}_{5} \mathrm{t}^{2}+\mathrm{p}_{6} * \mathrm{t}+\mathrm{p}_{7}$

where $\mathrm{p}_{5}, \mathrm{p}_{6}$, and $\mathrm{p}_{7}$, are constants observed from regression analysis and $\mathrm{t}$ is the rehydration time in minutes.

\subsection{Modelling The rehydration data}

The experimental rehydration kinetics data were fitted to the equations 4, 5, 6 and 7 to determine the model that best describes the rehydration kinetics of the yam slices.

Peleg

$$
M_{t}=M_{o}+(t /(a+b t)
$$

Weibull

$$
M_{t}=M_{o}\left[1-\exp \left(-(t / \alpha)^{\beta}\right)\right]
$$

Exponential

$$
\begin{aligned}
& M_{t}=\left(M_{0}-M_{e}\right) \exp \left(c t^{d}\right)+M_{e} \\
& M_{t}=g \exp (h t)+j \exp (q t)
\end{aligned}
$$

New Model

$$
\text { atime } M_{0} \text { is the initial moist }
$$

where $M_{t}$ is the moisture contents at time $t, M_{o}$ is the initial moisture content, $M_{e}$ is the equilibrium moisture content, and $\alpha, \beta, \mathrm{a}, \mathrm{b}, \mathrm{c}, \mathrm{d}, \mathrm{g}, \mathrm{h}, \mathrm{j}$, and $\mathrm{q}$ are constants observed from regression analysis

For quality fit, the coefficient of determination $\left(\mathrm{R}^{2}\right)$, should be closest to unity while the sum of square-error (SSE), and the root-mean-square-error (RMSE) should closest to zero. The methods of estimating $\mathrm{R}^{2}$, SSE and RMSE are discussed extensively in the literature ${ }^{[18 \text {, }}$ 19]. In this work, the software package from Matrix Laboratory (MATLAB) was used to perform the statistical analysis. 


\section{RESULTS AND DISCUSSIONS}

\subsection{Evaluation of the Rehydration Ratio models}

Four sets of rehydration experiments were performed at rehydration water temperatures of $27,40,60$, and $80^{\circ} \mathrm{C}$. The rehydration ratio at each rehydration time was calculated according to equation 1 using the weight data obtained during the rehydration experiments. Table 1 presents the statistical parameters when the rehydration ratios were correlated with rehydration time according to equations of the form given in equation 2 and 3 . Table 1 clearly indicates that the two-term exponential model fits the rehydration ratio vs. time data better than the polynomial model. For the two-term exponential equation form, the $\mathrm{R}^{2}$ values were closer to unity and the SSE and RMSE values were closer to zero than the polynomial equation form. Table 2 shows the constants obtained with a 95\% confidence bound, by fitting the rehydration ratio data to the exponential equation form presented in equation 2.

Table 1 Statistical Parameters for Yam when correlating Rehydration Ratios with Rehydration

Time at different temperature

Exponential Equation Form Polynomial Equation Form

\begin{tabular}{llllcccc}
\hline S/N & Water Temp. & \multicolumn{1}{c}{ R2 } & RMSE & SSE & R2 & RMSE & SSE \\
\hline 1 & $27^{\circ} \mathrm{C}$ & 0.9966 & 0.0180 & 0.0032 & 0.9245 & 0.0808 & 0.0719 \\
2 & $40^{\circ} \mathrm{C}$ & 0.9860 & 0.0311 & 0.0097 & 0.9447 & 0.0591 & 0.0384 \\
3 & $60^{\circ} \mathrm{C}$ & 0.903 & 0.0214 & 0.0046 & 0.9420 & 0.0501 & 0.0276 \\
4 & $80^{\circ} \mathrm{C}$ & 0.9864 & 0.0317 & 0.0100 & 0.9803 & 0.0364 & 0.0146 \\
\hline
\end{tabular}

Table 2 Constants For The Models Obtained By Fitting Rehydration Data The Exponential Equations and Polynomial Model For Yam Slices

\begin{tabular}{|c|c|c|c|}
\hline $\mathbf{S} / \mathbf{N}$ & Temp. & Exponential Model Constants & Polynomial Model Constants \\
\hline 1 & $27^{\circ} \mathrm{C}$ & $\begin{array}{l}\mathrm{p}_{1}=1.921 \pm 0.052 \\
\mathrm{p}_{2}=0.000752 \pm 0.00015315 \\
\mathrm{p}_{3}=-0.8875 \pm 0.09005 \\
\mathrm{p}_{4}=-0.04318 \pm 0.00888\end{array}$ & $\begin{array}{l}\mathrm{p}_{5}=-2.041 \mathrm{e}-05+1.07 \mathrm{E}-05 \\
\mathrm{p}_{6}=0.00813 \pm 0.002628 \\
\mathrm{p}_{7}=1.45 \pm 0.1255\end{array}$ \\
\hline 2 & $40^{\circ} \mathrm{C}$ & $\begin{array}{l}\mathrm{p}_{1}=2.077 \pm 0.114 \\
\mathrm{p}_{2}=0.0006457 \pm 0.0002971 \\
\mathrm{p}_{3}=-0.6219 \pm 0.13385 \\
\mathrm{p}_{4}=-0.03468 \pm 0.017725\end{array}$ & $\begin{array}{l}\mathrm{p}_{5}=-1.543 \mathrm{e}-05 \pm 7.80 \mathrm{E}-06 \\
\mathrm{p}_{6}=0.006547 \pm 0.00192 \\
\mathrm{p}_{7}=1.691 \pm 0.092\end{array}$ \\
\hline 3 & $60^{\circ} \mathrm{C}$ & $\begin{array}{l}\mathrm{p}_{1}=2.116 \pm 0.04 \\
\mathrm{p}_{2}=0.0008455 \pm 0.00011835 \\
\mathrm{p}_{3}=-0.4871 \pm 0.23 \\
\mathrm{p}_{4}=-0.0761 \pm 0.044295\end{array}$ & $\begin{array}{l}\mathrm{p}_{5}=-5.903 \mathrm{e}-06+5.90 \mathrm{E}-06 \\
\mathrm{p}_{6}=0.003884+0.0016265 \\
\mathrm{p}_{7}=1.975 \pm 0.078\end{array}$ \\
\hline 4 & $80^{\circ} \mathrm{C}$ & $\begin{array}{l}\mathrm{p}_{1}=2.152 \pm 0.1395 \\
\mathrm{p}_{2}=0.0009701 \pm 0.00033105 \\
\mathrm{p}_{3}=-0.3082 \pm 0.1325 \\
\mathrm{p}_{4}=-0.0285 \pm 0.0284985\end{array}$ & $\begin{array}{l}\mathrm{p}_{5}=-7.178 \mathrm{e}-06 \pm 4.815 \mathrm{E}-06 \\
\mathrm{p}_{6}=0.004868 \pm 0.0011835 \\
\mathrm{p}_{7}=1.936 \pm 1.993\end{array}$ \\
\hline
\end{tabular}


Fig. 1 shows a plot of the variation in the experimental and the predicted (Exponential) rehydration ratio with drying time at different temperatures for white yam. The plots of the experimental and predicted rehydration ratios vs. time are observed as expected to be a good fit as expected from the regression analysis shown in Table 1.

\subsection{Evaluation of the Rehydration kinetics models}

The moisture content data obtained from the rehydration experiments were fitted to the New Model, the Weibull model, the Peleg model, and the Exponential model presented in equations 4, 5, 6 and 7. Table 3 presents the statistical results of correlating the moisture content rehydration data using the Peleg, Weibull, and Exponential and New models. For quality fit, the model chosen to best fit the rehydration kinetics of the yam slices is the one that meets the following three criteria: $\mathrm{R}^{2}$ is closest to unity, and SSE and RMSE are closest to zero. While most of the models fitted the moisture content experimental data with a coefficient of variance values exceeding 0.9600 , the $\mathrm{R}^{2}$ for the New model was the one closest to unity for all the temperatures. For the experiments performed at $27^{\circ} \mathrm{C}, 40^{\circ} \mathrm{C}$, $60^{\circ} \mathrm{C}$, and $80^{\circ} \mathrm{C}, \mathrm{R}^{2}$ exceeded 0.995 for the New model.

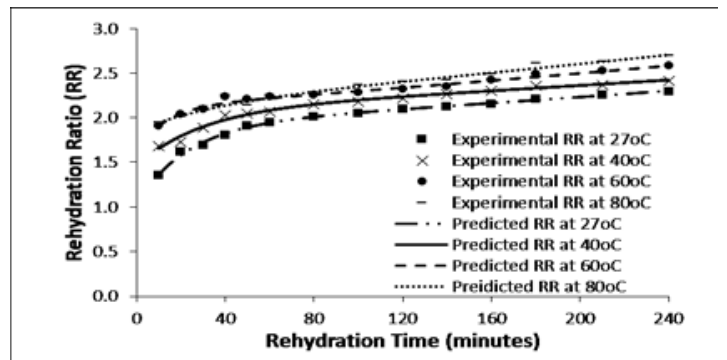

Fig. 1 Variation in Rehydration Ratio with Drying Time at Different Temperatures for white yam

Table 3 Regression constants correlating the moisture content rehydration data using Different Models

\begin{tabular}{|c|c|c|c|c|c|c|c|c|c|c|}
\hline $\mathbf{S} / \mathbf{N}$ & Temp & Models & $\mathbf{R}^{2}$ & RMSE & SSE & $\mathrm{S} / \mathrm{N}$ & Temp & $\mathbf{R}^{2}$ & RMSE & SSE \\
\hline \multirow{4}{*}{1} & \multirow{4}{*}{$27^{\circ} \mathrm{C}$} & New & 0.997 & 1.511 & 15.00 & \multirow{4}{*}{3} & \multirow{4}{*}{$60^{\circ} \mathrm{C}$} & 0.996 & 1.596 & 25.46 \\
\hline & & Peleg & 0.995 & 2.772 & 92.19 & & & 0.952 & 4.866 & 284.15 \\
\hline & & Weibull & 0.977 & 6.089 & 444.92 & & & 0.976 & 3.454 & 143.19 \\
\hline & & Exponential & 0.976 & 6.234 & 466.40 & & & 0.976 & 3.473 & 144.73 \\
\hline \multirow{4}{*}{2} & \multirow{4}{*}{$40^{\circ} \mathrm{C}$} & New & 0.996 & 1.842 & 33.91 & \multirow{4}{*}{4} & \multirow{4}{*}{$80^{\circ} \mathrm{C}$} & 0.993 & 2.248 & 50.53 \\
\hline & & Peleg & 0.988 & 3.050 & 111.59 & & & 0.881 & 8.195 & 805.82 \\
\hline & & Weibull & 0.966 & 5.174 & 321.28 & & & 0.982 & 3.171 & 120.63 \\
\hline & & Exponential & 0.965 & 5.224 & 327.42 & & & 0.982 & 3.152 & 119.22 \\
\hline
\end{tabular}

Also, for the temperatures considered, the SSE, and RMSE, values were the least for the New model. The implications are that the New model best fits the rehydration data among the models examined. However, the SSE, and RMSE values are large. This implies that the model should only be used in the range of process conditions studied and should not be used for predictions outside that range. The coefficients obtained by fitting rehydration moisture content data to the new model for the yam slices is presented in Table 4. 
Table 4 Coefficients Obtained By Fitting Rehydration Moisture content Data to the New Model For Yam Slices

\begin{tabular}{clcccc}
\hline $\mathbf{S} / \mathbf{N}$ & $\mathbf{T e m p}$ & $\mathbf{2 7}^{\mathbf{0}} \mathbf{C}$ & $\mathbf{4 0}^{\mathbf{}} \mathbf{C}$ & $\mathbf{6 0}^{\mathbf{0}} \mathbf{C}$ & $\mathbf{8 0}^{\mathbf{}} \mathbf{C}$ \\
\hline 1 & $\alpha$ & 99.76 & 46.11 & 24.63 & 17.3 \\
2 & $\beta$ & 0.5035 & 0.335 & 0.2729 & 0.3065 \\
3 & $\mathrm{a}$ & 0.1588 & 0.06158 & 0.0321 & 0.03559 \\
4 & $\mathrm{~b}$ & $5.133 \mathrm{e}-3$ & $5.282 \mathrm{e}-3$ & $05.215 \mathrm{e}-3$ & $4.904 \mathrm{e}-3$ \\
5 & $\mathrm{c}$ & -0.0935 & -0.2692 & -0.408 & -0.4084 \\
6 & $\mathrm{~d}$ & 0.5118 & 0.339 & 0.2757 & 0.3096 \\
7 & $\mathrm{~g}$ & 136.1 & 154.6 & 164.2 & 176.1 \\
8 & $\mathrm{~h}$ & $1.177 \mathrm{e}-3$ & $8.899 \mathrm{e}-4$ & $7.985 \mathrm{e}-4$ & $8.05 \mathrm{e}-4$ \\
9 & $\mathrm{~J}$ & -128.4 & -116.8 & -85.58 & -59.72 \\
10 & $\mathrm{q}$ & -0.03772 & -0.06141 & -0.06353 & -0.03705 \\
\hline
\end{tabular}

To further validate that the new rehydration model best fits the moisture content rehydration data, a simple linear regression analysis was performed between the experimental and predicted rehydration values. The relationship between the experimental and predicted rehydration moisture content values is also presented in Table 5.

Table 5 Relationship Between the Experimental and Predicted Rehydration Moisture Content Values

\begin{tabular}{ccccc}
\hline S/N & & Temp. & Equation & $\mathbf{R}^{2}$ \\
\hline 1 & 27 & $P M C=0.9991 E M C$ & 0.9945 \\
2 & 40 & $P M C=0.9997 E M C$ & 0.9962 \\
3 & 60 & $P M C=1.0018 E M C$ & 0.9977 \\
4 & 80 & $P M C=0.9998 E M C$ & 0.9925 \\
\hline
\end{tabular}

where $P M C$ is the predicted moisture content and $E M C$ is the experimental moisture content

Fig 2 shows the variation in moisture content of the yam samples with time rehydrated at different temperatures.

Fig 2 Variation in Moisture contents of yam with rehydration time at $27,40,60$, and $80^{\circ} \mathrm{C}$

The plots show that for any given time, the moisture content of the yam sample is higher as temperature increases. The plots show that as the rehydration temperature increases the extent of rehydration increases. In the first ten minutes, the moisture content of the yam slices for rehydration temperatures of $27,40,60$ and $80^{\circ} \mathrm{C}$ are $46.69,91.53,120.41$, and 137.87 g-water/g-solid respectively. There is a 3-fold magnitude in the moisture content of the samples rehydrated with a water temperature of $80^{\circ} \mathrm{C}$ over the moisture content of sample rehydrated at $27^{\circ} \mathrm{C}$. However, after about 240 minutes, the difference in the magnitude of the moisture contents decreases; the moisture content ranged from 179.02 212.60 g-water/g-solid for rehydration done in the temperature range of $27-80^{\circ} \mathrm{C}$.

\section{Conclusions}

White yam (Dioscorea rotundata) slices, $3.0 \mathrm{~mm}$ thick, were dehydrated in a Refractance Window $^{\mathrm{TM}}$ dryer. The dehydrated yam slices were rehydrated at $27,40,60$ and $80^{\circ} \mathrm{C}$. Mass and moisture content variation data with time were collected. By fitting the mass 
rehydration data to rehydration ratio models and the moisture content rehydration data to rehydration kinetics data, the following are the conclusions,.

The two-term exponential equation fits the rehydration ratio variation data better than the second order polynomial equation proposed by Singh and Pandey ${ }^{[17]}$. For the rehydration temperatures considered, the $\mathrm{R}^{2}$ values for the two-term exponential equation were closest to unity in all cases. For the samples rehydrated at $27,40,60$ and $80^{\circ} \mathrm{C}, \mathrm{R}^{2}$, for the two-term exponential equations was $0.9966,0.9860,0.9903$, and 0.9864 respectively as opposed to 0.9245, 0.9447, 0.9420 and 0.9803 for the second-order polynomial equation. Also, for the samples rehydrated at $27,40,60$ and $80^{\circ} \mathrm{C}$, the root-mean-square-error (RMSE) were $0.0180,0.0311,0.0214$ and 0.0317 respectively and the sum-of-squared-error (SSE) were $0.0032,0.0097,0.0046$ and 0.0100 respectively. All the RMSE and SSE values are close to zero.

When rehydrating the slices, the mass (Fig. 1) and moisture content (Fig. 2) values reached higher values for the same rehydration time as the temperature increased. The rehydration ratio and moisture content for the slices rehydrated at $80^{\circ} \mathrm{C}$ were about $50 \%$ higher for samples rehydrated at $27^{\circ} \mathrm{C}$ after ten minutes.

For the moisture rehydration data, the new model better fits the rehydration kinetics than the Peleg, Weibull and Exponential rehydration models for the process temperatures studied. Among the models investigated, the $\mathrm{R}^{2}$ value for the new models was closest to unity for all the process temperatures studied.

\section{References}

[1] United States Department of Agriculture (USDA), (2017a), Agricultural Research Service USDA Food Composition Databases, Retrieved August 30, 2017 from https://ndb.nal.usda.gov/ndb/foods/show/3266?man=\&lfacet=\&count=\&max=\&qlook up $=$ \&offset $=\&$ sort $=\&$ format $=$ Abridged $\&$ reportfmt $=$ other \&rptfrm $=\&$ ndbno $=\&$ nutrient $1=\&$ nutrient $2=\&$ nutrient $3=\&$ subset $=$ \& totCount $=\&$ measureby $=\& Q v=1 \& Q 6170=1 \& Q$ $\mathrm{v}=21 \& Q 6170=1$

[2] United States Department of Agriculture (USDA), (2017b), Agricultural Research Service USDA Food Composition Databases, Retrieved August 30, 2017 from https://ndb.nal.usda.gov/ndb/foods/show/3207?fg=\&manu=\&lfacet=\&format=\&count $=\& \max =50 \&$ offset $=\&$ sort $=$ default $\&$ order $=$ asc $\&$ qlookup=potato $\% 2 \mathrm{C}+$ raw $\& d s=\& q \mathrm{t}=$ $\& q p=\& q a=\& q n=\& q=\& i n g=$

[3] Hackett, A. F., Rugg-Gunn, A. J., Appleton, D. R. and Coombs, A., (1986), Dietary sources of energy, protein, fat and fibre in 375 English adolescents, Human Nutrition. Applied Nutrition [01 Jun 1986, 40(3):176-184]

[4] Subar, A. F., Krebs-Smith, S. M., Cook, A. and Kahle, L. L., (1998a), Dietary sources of nutrients among US children, 1989-1991, Pediatrics, Volume 102 No. 4 October 1998

[5] Subar, A. F., Krebs-Smith, S. M., Cook, A. and Kahle, L. L., (1998b), Dietary sources of nutrients among US adults, 1989 to 1991, Journal of the American Dietetic Association, Volume 98, Issue 5, May 1998, Pages 537-547. 
[6] Reedy, J. and Krebs-Smith, S. M., (2010), Dietary Sources of Energy, Solid Fats, and Added Sugars Among Children and Adolescents in the United States, J Am Diet Assoc. 2010 October; 110(10): 1477-1484. doi:10.1016/j.jada.2010.07.010.

[7] Marinos-Kouris, D., Maroulis, Z. B., and Kiranoudis, C. T., (1996), Computer Simulation of Industrial Dryers, Drying Technology: An International Journal, 14:5, 971-1010, DOI: 10.1080/07373939608917137

[8] Vagenas, G. K. and Marinos-Kouris, D., (1991), The Design and Optimization of an Industrial Dryer for Sultana Raisins, Drying Technology: An International Journal, 9:2, 439-461, DOI: 10.1080/07373939108916675

[9] Gowen, A., Abu-Ghannam, N., Frias, J., \& Oliveira, J. (2007). Influence of preblanching on the water absorption kinetics of soybeans. Journal of Food Engineering, 78(3), 965-971.

[10] García-Pascual, P., Sanjuán, N., Melis, R., \& Mulet, A. (2006). Morchella esculenta (morel) rehydration process modelling. Journal of Food Engineering, 72(4), 346-353.

[11] Machado, M. F., Oliveira, F. A., \& Cunha, L. M. (1999). Effect of milk fat and total solids concentration on the kinetics of moisture uptake by ready-to-eat breakfast cereal. International journal of food science \& technology, 34(1), 47-57.

[12] Marabi, A., Livings, S., Jacobson, M., \& Saguy, I. S. (2003). Normalized Weibull distribution for modeling rehydration of food particulates. European Food Research and Technology, 217(4), 311-318.

[13] Kashaninejad, M., Maghsoudlou, Y., Rafiee, S., \& Khomeiri, M. (2007). Study of hydration kinetics and density changes of rice (Tarom Mahali) during hydrothermal processing. Journal of Food Engineering, 79(4), 1383-1390.

[14] Misra, M. K., \& Brooker, D. B. (1980). Thin-layer drying and rewetting equations for shelled yellow corn. Transactions of the ASAE, 23, 1254-1260.

[15] Saguy, I. S., Marabi, A., \& Wallach, R. (2005). New approach to model rehydration of dry food particulates utilizing principles of liquid transport in porous media. Trends in Food Science \& Technology, 16(11), 495-506.

[16] OHAUS Corporation, (2011), Instruction Manual MB45 Moisture Analyzer, OHAUS Corporation, 7 Campus Drive, Suite 310, Parsippany, NJ 07054 USA.

[17] Singh, N. J., Pandey, R. K., (2011), Rehydration characteristics and structural changes of sweet potato cubes after dehydration, American. Journal of Food Technology 6 (8): 709-716

[18] Ogunnaike, B. A., (2011). Random Phenomena: Fundamentals of Probability and Statistics for Engineers. CRC Press.

[19] Johnson, R. A., (2017), Miller and Freund's Probability and Statistics for Engineers. Pearson Education (C) 2017. ISBN 10: 1-292-17601-6, ISBN 13: 978-1-292-17601-7. 